\title{
Simulatiepatiënten of gestandaardiseerde patiënten? Voortschrijdend inzicht in overeenkomsten en verschillen
}

\author{
E.M. van Weel-Baumgarten, A.M. Hettinga, E. Plattel-van Os
}

\section{Samenvatting}

Simulatiepatiënten (SP) en gestandaardiseerde patiënten (GP) worden in het medisch onderwijs veelvuldig ingezet voor communicatievaardigheidstrainingen en toetsing. In de literatuur blijken de twee termen vaak door elkaar gebruikt te worden. Op basis van de ervaringen met de inzet van SP'en en GP'en in de opleiding Geneeskunde in Nijmegen door de jaren heen, beoogt dit artikel meer helderheid te geven over de overeenkomsten en verschillen tussen beide groepen. In het Nijmeegse onderwijs worden SP'en gebruikt in vaardigheidstrainingen in de lijn Communicatie en Consultvoering $(C \& C)$, zowel in de bachelor-als masteropleiding. Hierbij is veel aandacht voor het integreren van communicatie met medische inhoud. De inzet van SP'en is vooral geschikt bij de training van studenten en bij formatieve beoordeling. GP'en worden ingezet bij toetsing en onderzoek; in Nijmegen betreft dit toetsing binnen en buiten de opleiding Geneeskunde waaronder de Deeltoets Klinische Vaardigheden (DKV): een landelijke toets die deel uitmaakt van de toetsingsprocedure voor buitenslands gediplomeerde artsen van buiten de Europese Unie en de Europese Economische Ruimte.

Overeenkomsten tussen SP'en en GP'en zijn er onder andere in de selectiecriteria, in de trainingsvorm en in het trainen dan wel beoordelen van (communicatie)vaardigheden. Verschillen zijn er vooral in de variatie in, en in de manier van het spelen van de rollen. SP'en mogen variëren, GP'en niet. Ook ten aanzien van het type beoordeling is er verschil: bij simulatiepatiënten betreft het vooral formatieve beoordelingen; gestandaardiseerde patiënten worden bij summatieve beoordeling ingezet. (Weel-Baumgarten EM van, Hettinga AM, Plattel-van Os E. Simulatiepatiënten of gestandaardiseerde patiënten? Voortschrijdend inzicht in overeenkomsten en verschillen. Tijdschrift voor Medisch Onderwijs 2011;30(5):237-245.)

\section{Inleiding}

Om een goede arts-patiëntrelatie te kunnen opbouwen moet elke arts beschikken over de juiste, patiëntgerichte communicatievaardigheden. Dit is niet alleen belangrijk voor de tevredenheid van zowel arts als patiënt maar ook omdat een dergelijke relatie, naast kennis en andere competenties, nodig is om optimale gezondheidsuitkomsten te realiseren. ${ }^{1-2}$ Communicatie is dan ook een van de belangrijke criteria in het oorspronkelijke Raamplan van de opleiding Geneeskunde en in alle volgende herzieningen, en is tevens een van de CanMeds competenties. ${ }^{3-4}$ Dientengevolge hebben alle faculteiten Geneeskunde in Nederland, en in veel andere plaatsen in de wereld, de laatste decennia in hun opleiding communicatiecurricula en -trainingen op dit gebied opgenomen. Het is inmiddels ook duidelijk dat het mogelijk is studenten, artsen in opleiding tot specialist en praktiserend artsen communicatievaardigheden aan te leren, en dat vaardigheidstrainingen en ervaringsleren daarvoor de meest geschikte methoden zijn. ${ }^{5}$

Zelf oefenen en gerichte feedback ontvangen zijn essentieel om goed, patiëntgericht en met een persoonlijke stijl te leren communiceren. Ervaringsleren aan de hand 
van gesprekken met echte patiënten in de praktijk lijkt het allerbeste, omdat dit is wat artsen moeten kunnen. Voorwaarde is dat tijdens dit leerproces wel observatie mogelijk moet zijn en er feedback gegeven kan worden op de gesprekken. Omdat dit lang niet altijd, en zeker niet op grote schaal, te realiseren valt, wordt al langere tijd voor vaardigheidsonderwijs in communicatie, naast andere methodieken zoals het rollenspel, gebruik gemaakt van simulatiepatiënten (SP). SP'en blijken goed te kunnen worden getraind in het spelen van een rol en in het geven van feedback en zijn daarmee docent- en patiëntsparend. Zij zijn naar behoefte in te roosteren op momenten dat dit voor het onderwijs nodig is, terwijl het aanbod van echte, voor dit onderwijs 'geschikte' patiënten aan het toeval moet worden overgelaten. Medewerking in onderwijs is voor veel patiënten wel maar voor SP'en niet belastend, en inzet van echte patiënten is vooral bij de huidige studentenaantallen in Nederland meestal niet op grote schaal mogelijk. Dit zijn belangrijke argument om gebruik te maken van SP'en.

Personen die worden ingezet om een patiëntenrol te spelen worden met succes gebruikt voor medisch onderwijs, toetsing en onderzoek. In de literatuur blijken de termen simulatie- en gestandaardiseerde patiënten vaak door elkaar heen gebruikt te worden al worden er ook verschillen beschreven. De term simulatiepatiënten wordt vooral gebruikt als het over onderwijs gaat. SP'en mogen tijdens onderwijs flexibel zijn in het spelen van een rol. Gestandaardiseerde patiënten (GP'en) worden geacht hun rol elke keer exact hetzelfde neer te zetten en hun inzet is vooral geschikt bij toetsing en in vergelijkende onderzoeken. ${ }^{6-9}$ Zie voor een definitie Box 1.

Dit artikel beoogt helderheid te verschaffen over de belangrijkste overeenkomsten en verschillen tussen SP'en en GP'en zoals deze in Nijmegen in de loop van de tijd zijn ontstaan. We richten ons op het verschil in inzet, (training in) rol, ingangsselectiecriteria, feedback en beoordeling. In onze beschrijving zullen we het begrip feedback hanteren wanneer het gaat over formatieve beoordeling in het onderwijs en beoordeling als het gaat om summatieve beoordeling in het toetsen.

Box 1. Definitie SP en GP.

Simulatiepatiënten (SP) en gestandaardiseerde patiënten (GP) zijn mensen die getraind zijn om geloofwaardig de rol van patiënt te spelen met de symptomen en problemen van het bijbehorende scenario.

\section{Context}

In Nijmegen wordt in de opleiding Geneeskunde sinds 1987 gebruik gemaakt van SP'en in het onderwijs. Aanvankelijk gebeurde dit op beperkte schaal en voor slechts één onderwerp: het oefenen van een heteroanamnese kindergeneeskunde met behulp van simulatiemoeders. Al snel werd dit uitgebreid naar meer vakgebieden en soorten gesprekstrainingen, mede op verzoek van studenten die deze methodiek zeer waardeerden. Bovendien werd hun inzet in het onderwijs aan het eind van de jaren tachtig van de vorige eeuw uitgebreid met inzet bij de toetsing. In die tijd werden dezelfde SP'en voor beide doeleinden gebruikt, waarbij voor onderwijs en toetsing grotendeels dezelfde voorbereiding werd gegeven.

Bij de invoering van het curriculum 1995 werd voor het vaardigheidsonderwijs voor het eerst, in plaats van losstaande modules, een longitudinaal communicatiecurriculum ontwikkeld met veel meer oefeningen en toetsingsmomenten met rolspelers. Dit leidde ertoe dat er een verschil begon te ontstaan tussen rolspelers voor inzet in het 
onderwijs en bij de toetsing. Rolspelers die worden ingezet bij de toetsing zullen wij vanaf hier GP noemen.

\section{Onderwijs - inzet van simulatie- patiënten}

\section{Inzet en rollen}

In Nijmegen worden SP'en op grote schaal ingezet in vaardigheidstrainingen in de lijn Communicatie en Consultvoering ( $\& \& C)$ met veel aandacht voor integratie van communicatie met de medische inhoud. Deze lijn start aan het einde van de bacheloropleiding in jaar drie, in een blok met een gevarieerd aanbod aan vaardigheidstrainingen (PKO-1, Praktisch Klinisch Onderwijs). Ze loopt door tot aan het begin van jaar zes (in de masteropleiding), in een programma Centraal Klinisch Onderwijs (CKO) dat alterneert met de coschappen.

De $C \& C$ trainingen vinden doorgaans plaats in twee groepen van 15 of in drie groepen van 12 studenten onder begeleiding van communicatiedocenten (artsen en psychologen). Voor het oefenen met SP'en worden de studenten vervolgens, op enkele uitzonderingen na waarbij het een groepsoefening betreft, verder opgedeeld in kleine groepen van drie of vier studenten. Na een gezamenlijke inleiding door een der docenten oefent elke kleine groep achtereenvolgens drie tot zes gesprekken, afhankelijk van het soort gesprek en de daarvoor afgesproken duur. De oefening heeft een carrouselvorm waarbij zowel de verschillende SP'en met verschillende casuïstiek alsook de docenten over de kleine groepen rouleren. De student krijgt direct feedback van de SP en van de eventueel in die ronde aanwezige docent (arts of psycholoog). Elke student komt minimaal één keer zelf aan de beurt, waarbij tijdens de feedback de gelegenheid bestaat opnieuw te oefenen met alternatieve communicatie in de betreffende casus. In de gesprekken van de medestudenten is de student actief betrokken bij de feedback. Aan het eind van elke training van doorgaans een dagdeel is er een plenaire afsluiting waarin met de docenten resterende vragen kunnen worden besproken en de belangrijkste leerpunten worden samengevat.

Er is door het programma heen een grote variatie in rollen, zowel medisch-inhoudelijk als wat betreft communicatievaardigheid en patiëntengroep/populatie (Tabel 1).

\section{Selectie en training}

Om de SP'en hun rollen correct te kunnen laten spelen en vooral om hen op niveau feedback te kunnen laten geven, hanteren wij een $\mathrm{HBO}$ werk- en/of denkniveau als selectiecriterium voor inzet van SP'en in het onderwijs.

Voor enkele $\mathrm{C} \& \mathrm{C}$ trainingen met heel lastige consulten worden alleen professionele acteurs gebruikt. Dit betreft alleen trainingen waarbij ad hoc in het spel geïmproviseerd moet kunnen worden en snel extreme situaties moeten kunnen worden uitgebeeld, zoals wanneer studenten eigen casuïstiek inbrengen waarmee geoefend moet worden. Voor deze functie worden vanwege de benodigde acteervaardigheden alleen acteurs met een afgeronde opleiding als (trainings)acteur aangenomen.

De basistraining voor de Nijmeegse SP'en duurt gemiddeld twaalf uur en bestaat uit uitleg en meekijken, rol- en feedbacktraining. Om natuurgetrouw een rol te kunnen neerzetten, krijgen SP'en in kleine groepen (twee à drie SP'en) een gedegen roltraining van twee uur van een coach (communicatietrainer). Daarbij oefenen zij meerdere malen met hulp van een student in het gedoseerd en op een natuurlijke manier prijsgeven van de in de rol beschreven informatie. In de trainingen is ook een (huis)arts aanwezig om de 'echtheid' van de rol mee te bewaken en uitleg te geven over de medische inhoud. 
Tabel 1. Inzet van simulatiepatiënten in het vaardigheidsonderwijs Communicatie en Consultvoering (C\&C) van het UMC St Radboud.

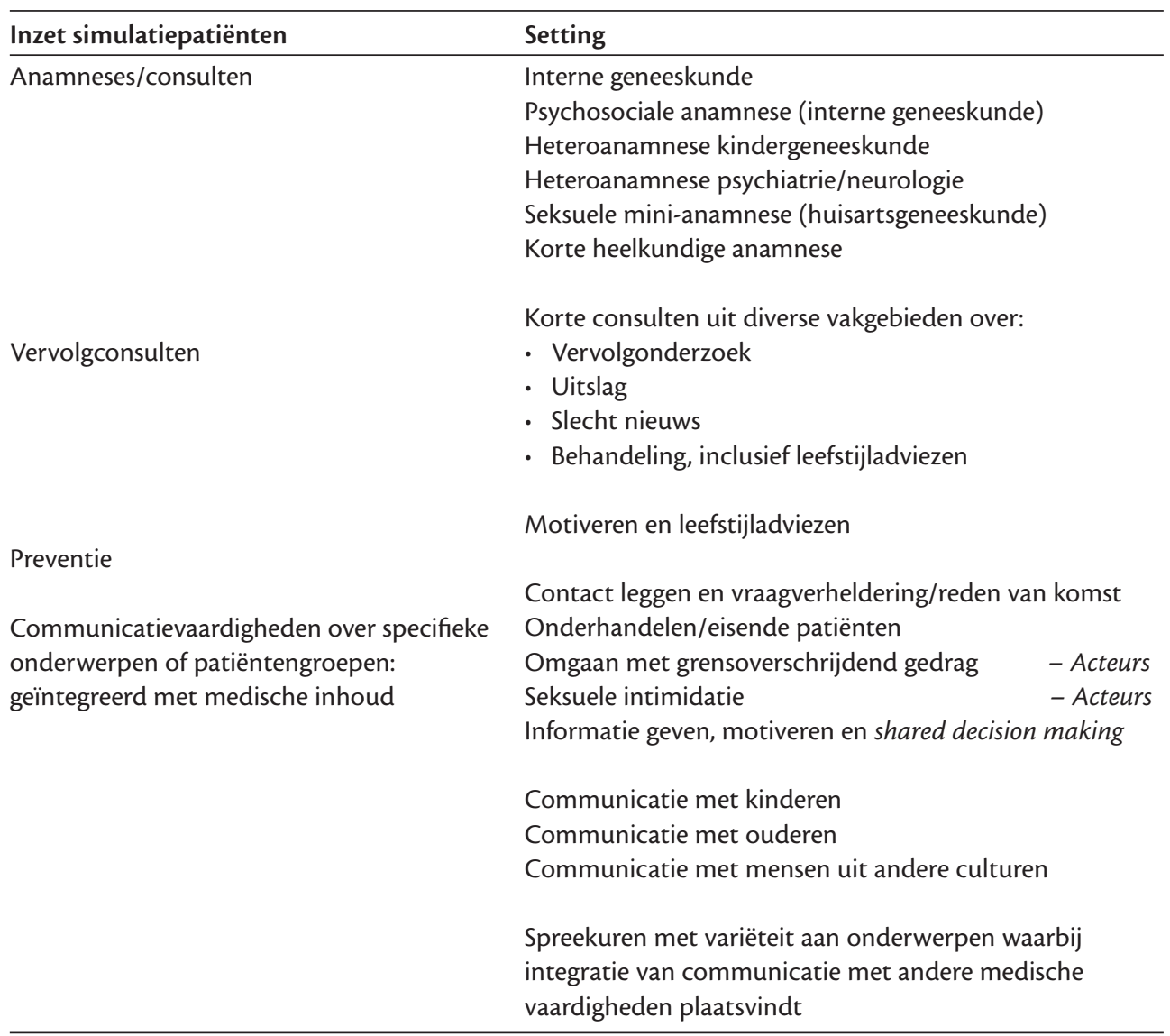

Hoewel voor het onderwijs leerdoelen beschreven staan voor elke werkgroep en daarnaast alle symptomen in de rol vastliggen, is er toch een grote spreiding in het neerzetten van de rol mogelijk. Juist vanwege de verschillen tussen studenten en het kunnen geven van feedback op maat, moet de SP kunnen meegaan met het niveau van de student.

SP'en mogen zich zoveel mogelijk gedragen zoals zij dat zelf in dit consult zouden hebben gedaan; ze worden er wel op getraind om de veiligheid van het leerklimaat in het spelen van de rol te bewaken, zelfs als studenten bij de SP irritatie opwekken of dreigen vast te lopen.

In enkele werkgroepen vindt ook een gericht lichamelijk onderzoek plaats of wordt bij de SP een verrichting uitgevoerd. Ook hierin worden de SP'en getraind zodat zij op het juiste moment op de juiste manier op vragen en onderzoek weten te reageren. Deze medisch-inhoudelijke training wordt door een van de artsen gegeven.

Om bij elk consult effectieve feedback aan de student te kunnen geven, ligt in de 
volgende SP-trainingen de nadruk op het aanleren daarvan. In ten minste drie bijeenkomsten van twee uur wordt onder begeleiding van de coach/communicatietrainer en met hulp van een student, met de diverse onderwerpspecifieke aandachtspunten voor feedback stapsgewijs geoefend in de basisregels van feedback en het geven van feedback op maat. ${ }^{10} \mathrm{Bij}$ een deel van deze training is, afhankelijk van het onderwerp, ook een arts of een psycholoog aanwezig. De focus van de feedback door de SP ligt op het patiëntperspectief. Daarbij zijn tijdens het onderwijs de vragen van de student leidend, maar ook de beleving van de SP.

Vanwege de integratie met medische inhoud worden de Nijmeegse SP'en getraind om ook beperkte feedback op medische inhoud te geven als er geen arts in de groep aanwezig is. Zij betrekken hiervoor de collega-studenten in de feedback als medisch deskundigen. Wel is de afspraak dat de feedback van de SP alleen medische aspecten betreft als de SP een duidelijke relatie kan leggen met de door de student gebruikte communicatie: SP'en leren in de training in hun feedback aan studenten concreet aan te geven door welke communicatieaspecten zij die medische inhoud prijsgaven of door welke aspecten zij zich in de werkelijkheid wel of niet aan de instructies van de arts zouden hebben gehouden. Dit werkt sterk motiverend en studenten kunnen, indien nodig, direct opnieuw oefenen met de alternatieven uit die feedback.

\section{Toetsing - inzet van gestandaardiseerde patiënten}

\section{Inzet en rollen}

In Nijmegen wordt in verschillende toetsen van de opleiding Geneeskunde gebruik gemaakt van stations met GP'en, waarbij artsen en psychologen de studenten beoorde- len op communicatie en medische inhoud. Om elke kandidaat dezelfde kansen te geven moet de GP, in tegenstelling tot de SP, in elke ronde de patiëntenrol exact hetzelfde neerzetten.

In alle toetsrollen, binnen en buiten het geneeskundeonderwijs, gaat het bij communicatie vooral om het beoordelen van basisvaardigheden. Soms brengt de inhoud van het consult toch communicatief lastige situaties met zich mee, zoals het omgaan met een eisende patiënt. Gemiddeld genomen zijn de toetsrollen voor communicatie echter minder gevarieerd dan de onderwijsrollen en datzelfde geldt voor de patiëntenpopulatie. Deze bestaat bij alle toetsen vooral uit Nederlandstalige volwassenen, waarbij de meer extreme communicatieconsulten (zoals grensoverschrijdend gedrag) niet aan de orde zijn.

Bij toetsen die buiten het onderwijs van de opleiding Geneeskunde vallen, beoordelen GP'en de studenten of artsen wel zelf. Een voorbeeld van een dergelijke toets met beoordeling door GP'en is de Deeltoets Klinische Vaardigheden (DKV) die sinds 2006 in Nijmegen wordt afgenomen. Dit is een landelijke toets die deel uitmaakt van de toetsingsprocedure voor buitenslands gediplomeerde artsen van buiten de Europese Unie en de Europese Economische Ruimte die in Nederland als arts geregistreerd willen worden. ${ }^{11}$ Deze toets is qua opzet vergelijkbaar met de vaardighedentoets in het kader van het certificatie-examen in de Verenigde Staten (de United States Medical Licensing Examination step 2, Clinical Skills). ${ }^{14}$ Kandidaten doorlopen op één dag tien stations met GP'en waarbij zij geacht worden een volledig consult uit te voeren, inclusief schriftelijke communicatie en verslaglegging. De DKV toetst op anamnese, lichamelijk onderzoek, communicatie, professioneel gedrag en schriftelijke verslaglegging. De beoordeling van anamnese, lichamelijk onderzoek, communicatie en 
professioneel gedrag wordt gedaan door GP'en die hierin uitgebreid getraind worden en hiertoe in staat blijken. ${ }^{12-13}$

\section{Selectie en training}

GP'en die worden ingezet bij de toetsen in het onderwijs beoordelen de studenten niet zelf en daarom zijn voor hun selectie geen andere criteria vastgelegd dan dat zij trainbaar zijn in het neerzetten van hun rol. Omdat in de externe toetsing, zoals in de DKV, gestandaardiseerde patiënten de kandidaten betrouwbaar moeten kunnen beoordelen, geldt hier hetzelfde criterium als in het onderwijs: een HBO denk- en werkniveau.

Om in alle toetsen de rollen natuurgetrouw te kunnen spelen, wordt ook aan GP'en een roltraining gegeven. Daarin wordt vooral gelet op de dosering waarmee zij de informatie prijsgeven en op het gegeven dat hiervoor zorgvuldig geluisterd moet worden naar de vragen van de arts. Een GP mag alléén op de gestelde vraag antwoord geven en niet spontaan nog meer relevante medische gegevens prijsgeven. Omdat voor toetsing standaardisering essentieel is om elke student of arts dezelfde kans te geven, bevatten alle toetsrollen een vaste openingszin, gevolgd door enkele vaste vervolgzinnen die kunnen worden gebruikt als daar in het consult ruimte voor is. Er wordt in de training uitvoerig geoefend in wat de rolspeler spontaan mag noemen, en welke symptomen alleen bij navragen verteld mogen worden.

Omdat de beoordeling van de medischinhoudelijke kanten (anamnese en lichamelijk onderzoek) van de casus in externe toetsen met beoordeling (zoals de DKV) door de GP wordt gedaan (summatief) is het nodig op een natuurlijke presentatie van die symptomen en het lichamelijk onderzoek te trainen. Afwijkende symptomen worden voorgedaan en toegelicht en een arts laat zien wat adequate en niet adequate manieren van het betreffende lichamelijk onderzoek zijn.

De training voor deze externe toetsen wordt gegeven door twee instructeurs: een communicatietrainer en een arts. Het is een aanvullende training van twee sessies van twee uur waarin met een student geoefend wordt in het spelen van de rol. Alle GP'en voor deze toetsen hebben in een eerder stadium de uitgebreide basistraining ontvangen.

Tevens wordt veel aandacht besteed aan het leren beoordelen. GP'en oefenen herhaaldelijk en onder begeleiding hoe zij de bij de toets behorende scorelijsten correct moeten invullen. Met behulp van deze gedetailleerde scorelijsten en met deze zorgvuldige training blijkt het mogelijk deze beoordeling betrouwbaar door GP'en te laten doen, ook wat betreft de medische inhoud. ${ }^{15}$ In het kader van kwaliteitsbewaking en de mogelijkheid tot terugzien van de toetsconsulten, worden bij de DKV alle consulten op video opgenomen.

Voor elke toetsdag (de deeltoets vindt minimaal drie maal per jaar plaats) wordt een opfristraining gegeven waarbij aan de hand van een video van een consult van een eerdere toets opnieuw wordt geoefend in het beoordelen van de kandidaat. Hierbij wordt de kwaliteit van het spelen van de rol beoordeeld en zo nodig een aanvullende training gegeven om de rol zo natuurlijk mogelijk weer te geven.

\section{Samenvatting overeenkomsten en verschillen tussen simulatiepatiënten en gestandaardiseerde patiënten}

Uit de voorafgaande beschrijving komen overeenkomsten en verschillen tussen SP'en en GP'en naar voren, als ook tussen GP'en met en zonder rol in de beoordeling. De belangrijkste overeenkomsten en verschillen zijn in Tabel 2 samengevat. 


\section{Conclusies}

Onderwijs en toetsing met inzet van simulatie- en gestandaardiseerde patiënten biedt studenten en artsen mogelijkheden zich te ontwikkelen in klinische vaardigheden. Dit heeft logistieke voordelen omdat SP'en en GP'en, mits goed geselecteerd en voorbereid, zowel de patiëntenrol als de docentenrol op zich kunnen nemen. Het is tevens van belang onderscheid te maken tussen SP'en en GP'en en tussen GP'en met en zonder rol in de beoordeling van de kandidaten. Naast overeenkomsten zijn er ook belangrijke verschillen. Deze verschillen

Tabel 2. Belangrijkste overeenkomsten en verschillen tussen simulatiepatiënten en gestandaardiseerde patiënten.

\begin{tabular}{|c|c|c|c|c|}
\hline & SP in onderwijs & $\begin{array}{l}\text { Trainingsacteur in } \\
\text { onderwijs }\end{array}$ & $\begin{array}{l}\text { GP in toetsing zonder } \\
\text { beoordeling door } \\
\text { de GP }\end{array}$ & $\begin{array}{l}\text { GP in toetsing met } \\
\text { beoordeling door } \\
\text { de GP } \\
\text { (o.a. de DKV) }\end{array}$ \\
\hline Selectie & $\mathrm{HBO}$ & $\begin{array}{l}\text { HBO; afgeronde } \\
\text { opleiding als } \\
\text { (trainings)acteur }\end{array}$ & Geen & $\begin{array}{l}\text { HBO; uit bestand SP } \\
\text { onderwijs }\end{array}$ \\
\hline Rol & Mag variëren & Mag variëren & Gestandaardiseerd & Gestandaardiseerd \\
\hline Duur training & $\begin{array}{l}\text { Basis } 12 \text { uur; } 2-4 \text { uur } \\
\text { voor elke nieuwe rol }\end{array}$ & $2-4$ uur & 2 uur & $\begin{array}{l}\text { Basis training }+2 \times 2 \text { uur } \\
\text { voor nieuwe rol. } 1^{\mathrm{e}} \\
\text { toetsdag begeleiding } \\
\text { door reeds ingetrainde } \\
\text { GP. } 2 \text { uur voor } \\
\text { opfristraining }\end{array}$ \\
\hline Vorm training & $\begin{array}{l}\text { Vaardigheidstraining } \\
\text { met oefenstudent en } \\
\text { feedback }\end{array}$ & $\begin{array}{l}\text { Vaardigheidstraining } \\
\text { met oefenstudent en } \\
\text { feedback }\end{array}$ & $\begin{array}{l}\text { Vaardigheidstraining } \\
\text { met oefenstudent en } \\
\text { feedback }\end{array}$ & $\begin{array}{l}\text { Vaardigheidstraining } \\
\text { met oefenstudent en } \\
\text { feedback }\end{array}$ \\
\hline $\begin{array}{l}\text { Formatieve } \\
\text { beoordeling } \\
\text { (feedback) }\end{array}$ & $\mathrm{Ja}$ & $\mathrm{Ja}$ & Nee & Nee \\
\hline $\begin{array}{l}\text { Summatieve } \\
\text { beoordeling } \\
\text { (scoren) }\end{array}$ & Nee & Nee & Nee & $\mathrm{Ja}$ \\
\hline $\begin{array}{l}\text { Communicatie- } \\
\text { vaardigheden }\end{array}$ & $\mathrm{Ja}$ & $\mathrm{Ja}$ & $\mathrm{Ja}$ & $\mathrm{Ja}$ \\
\hline $\begin{array}{l}\text { Medische } \\
\text { inhoud }\end{array}$ & $\mathrm{Ja}$ & Nee & $\mathrm{Ja}$ & $\mathrm{Ja}$ \\
\hline $\begin{array}{l}\text { Lichamelijk } \\
\text { onderzoek }\end{array}$ & Soms & Nee & Nee & $\mathrm{Ja}$ \\
\hline Betaling & $\begin{array}{l}\text { UMC-contract } \\
\text { schaal } 7\end{array}$ & $€ 50 /$ uur & $\begin{array}{l}\text { UMC-contract } \\
\text { schaal } 7\end{array}$ & $\begin{array}{l}\text { UMC-contract } \\
\text { schaal } 7\end{array}$ \\
\hline
\end{tabular}


betreffen kort samengevat niet alleen de ingangscriteria maar ook de training in de rol, in het geven van feedback en in het beoordelen. Onze ervaring leert dat niet elke SP alle beoordelings-/toetsingstaken even goed kan uitvoeren maar dat er een grote groep is die hiertoe met een zorgvuldige voorbereiding wel in staat is. Veel van onze GP'en waren al in het onderwijs betrokken en konden in betrekkelijk korte tijd getraind worden voor deze toetsingstaak.

Het is onder meer dankzij de NVMOwerkgroep 'Simulatie en gestandaardiseerde patiënten' bekend dat simulatiepatiënten op uiteenlopende wijzen worden ingezet in het medisch onderwijs. Het blijft echter lastig goed zicht te krijgen op de verschillende manieren waarop dit gebeurt. Wij hopen dat door deze beschrijving een brede uitwisseling van ervaringen op dit gebied op gang zal komen en zijn benieuwd waarin onze manier van inzet van de verschillende groepen simulatiepatiënten overeenkomt of verschilt met die in andere centra.

\section{Literatuur}

1. Di Blasi Z, Harkness E, Ernst E, Georgiou A, Kleijnen J. Influence of context effects on health outcomes: a systematic review. Lancet 2001;357(9258): 757-762.

2. Stewart M, Brown JB, Donner A, McWhinney IR, Oates J, Weston WW et al. The impact of patientcentered care on outcomes. J Fam Pract 2000; 49 (9):796-804.

3. Metz JC. Blueprint 1994: follow-up and implications. Eur J Morphol 2001;39(4):227-229.

4. Royal College of Physicians and Surgeons of Canada. The CanMEDS 2005 physician competency framework: Better standards, better physicians, better care. Royal College of Physicians and Surgeons of Canada; 2005.

5. Kurtz SM, Silverman J, Draper J. Teaching and learning communication skills in medicine. Oxford: Radcliffe medical press; 2005.
6. Donnelly MB, Sloan D, Plymale M, Schwartz R. Assessment of residents' interpersonal skills by faculty proctors and standardized patients: a psychometric analysis. Acad Med 2000; 75(10 Suppl):S93-95.

7. Norcini J, Boulet J. Methodological issues in the use of standardized patients for assessment. Teach Learn Med 2003; 15(4):293-297.

8. Burdick WP, Escovitz ES. Use of standardized patients in a freshman emergency medicine course. J Emerg Med 1992; 10(5):627-629.

9. Wallace J, Rao R, Haslam R. Simulated patients and objective structured clinical examinations: review of their use in medical education. Advances in Psychiatric Treatment 2002; 8:342-350.

10. Spaendonck K, Weel-Baumgarten EM. Feedback. Nijmegen: Universitair Publikatiebureau KUN. Proceedings Gezond Onderwijs congres 1993;2:62-65.

11. https://www ribiznl/registratie/meteenbuitenlandsdiploma/assessment/ [2011].

12. Hettinga AM, Plattel-van Os E, Postma CT. Het trainen van simulatiepatienten in een gestandaardiseerde rol en het trainen van simulatiepatienten in het beoordelen van klinische vaardigheden. Pre-conference workshop NVMO 2010. (zie: http://www.nvmo.nl/ resources/js/tinymce/plugins/imagemanager/files/ NVMO_boek_2010_LR.pdf, pagina 12). [Trainingsimulated patients to play a standardized role and training simulated patients to assess clinical skills].

13. Pelgrim EAM, Denessen EJPG, Hettinga AM, Postma CT. De kwaliteit van beoordelingen door simulatiepatiënten in een Objective Structured Clinical Examination (OSCE): een analyse van interbeoordelaarsovereenstemming. Tijdschrift voor Medisch Onderwijs 2009; 28(6):253-260. [The quality of assessment by standardized patients in an Objective Structural Clinical Examination (OSCE): an analysis of observer agreement. Netherlands Journal of Medical Education 2009; 28(6): 253-260].

14. http://www.usmle.org [2011].

15. Vleuten CPM van der, Luyk SJ van. Beoordelen van praktische vaardigheden. In: H.J.M. van Berkel \& A.E. Bax (red.). Beoordelen in het onderwijs: Een handleiding voor het construeren van toetsen en het evalueren van leerdoelen en onderwijsvormen. Houten/Zaventem: Bohn Stafleu van Loghum; 1993. [assessing practical skills assessment in education; a manual for test construction and evaluation of learning goals and educational formats]. 
De auteurs:

Dr. E.M. van Weel-Baumgarten, huisarts, onderzoeker en UHD, Afdeling Eerstelijnsgeneeskunde.*

Drs. A.M. Hettinga, huisarts en onderzoeker, Instituut voor Wetenschappelijke Opleidingen en Onderwijs (IWOO). * E. Plattel-van Os, coach communicatietrainer, Instituut voor Wetenschappelijke Opleidingen en Onderwijs (IWOO). *

* Allen zijn verbonden aan het UMC St Radboud Nijmegen.
Correspondentieadres:

E.M. van Weel-Baumgarten, Afdeling Eerstelijnsgeneeskunde ELG 161, UMC St Radboud, postbus 9101, 6500 HB Nijmegen. Tel.: 024-3610331. Fax: 024-3619561; e-maile.vanweel-baumgarten@elg.umcn.nl

Belangenconflict: geen gemeld

Financiële ondersteuning: geen gemeld

\section{Summary}

In medical education, simulated and standardised patients are frequently used for communication skills training and assessment. In the literature, the two terms are often used interchangeably. This article aims to clarify the differences and similarities between the two groups, based on more than two decades of experience at the Medical Faculty at Nijmegen, the Netherlands.

At Nijmegen, simulated patients are used in the longitudinal communication and consultation skills progamme in the undergraduate medical curriculum which emphasises the integration of communication skills and medical knowledge. Simulated patients role-play and give feedback in consultations with students. They are particularly suitable for training and formative assessment. Standardised patients are used for research and for summative assessments. In Nijmegen they contribute to assessments in the medical curriculum but also to external assessments, such as the 'clinical skills test' as part of the national exam of the Dutch medical licensure procedure for non-EU medical graduates.

We identified the following similarities between simulated and standardised patients: similar selection criteria and both groups receive intensive training and assess communication skills. Differences relate to the way they portray their roles and in the types of assessment in which they participate. Simulated patients are allowed to vary in their roles, whereas standardised patients are not. Simulated patients are used in formative assessments and standardised patients in summative assessments. (Weel-Baumgarten EM van, Hettinga AM, Plattel-van Os E. Simulated or standardised patients? Advancing insights into differences and similarities. Netherlands Journal of Medical Education 2011;30(5):237-245.) 